\title{
Identification Characteristics of Weathering Crust for Nephrite Gravel and its Imitation
}

\author{
Hui $\mathrm{Li}^{1, \mathrm{a}}$, Xuan Wang ${ }^{1, \mathrm{~b}}$, Yong Zhu ${ }^{1, \mathrm{c}}$, Zhengyu Zhou ${ }^{2}$ \\ ${ }^{1}$ Chongqing Academy of Metrology and Quality Inspection, Chongqing 401123, China \\ ${ }^{2}$ School of Ocean and Earth Sciences, Tongji University, Shanghai 200092, China \\ alihui@cqu.edu.cn, ${ }^{\text {b13667669535@163.com, }{ }^{\text {c}} 13883583338 @ 163 . c o m}$
}

Keywords: nephrite gravel; primary nephrite; imitation; crust color; identification

\begin{abstract}
The price of nephrite gravel (alluvial deposits nephrite) is becoming higher and higher duo to the growing market demand, and more and more imitations are produced. In this paper, nephrite gravel, primary nephrite with natural secondary weathering crust and artificial weathering crust imitation were tested by means of magnifier, gemological microscope, ultraviolet-visible absorption spectroscopy(UVS), and scanning electron microscopy and energy spectrometer (SEM-EDXRF) so as to explore the difference between natural and artificial weathering crust. The results show that nephrite gravel presents the surface features as "sweat pores" and "nail pattern" etc, and dendrite growth pattern for secondary weathering crust color, while the colors of dyed imitation are bright, and concentrate in the epidermis and fissures; the absorption peaks of natural black, yellow, and brown secondary weathering crust color are related to $\mathrm{Fe}^{+3}$ and $\mathrm{Fe}^{+2}$ for lightwave selective absorption, while artificially weathering crust imitation presents the large absorption band extending from the ultraviolet to the visible region, and Fe and Mn are not detected by SEM-EDXRF, which can be used as evidence for identification of the nephrite gravel and its imitation.
\end{abstract}

\section{Introduction}

Nephrite produced in China, Russia, South Korea, Australia, New Zealand, Canada, Brazil and Americaetc etc, it is famous in China. Nephrite gravel is alluvial deposits nephrite which stripped naturally from the primary ore, and secondary weathering and transport into the river. Nephrite gravel is the most precious in all varieties of nephrites and its price is higher and higher duo to the growing market demand, and more and more imitations are produced. The density, refractive index, hardness and main chemical composition of nephrite gravel, primary nephrite with natural weathering crust and artificial dyeing imitation are basically the same, so it is very difficult to identify nephrite gravel from primary nephrite with natural weathering crust and artificial weathering crust imitation only based on the gemological parameters and the chemical compositions. At present, scholars have carried on a lot of research on physical properties, mineral composition, structural features and genetic mechanism etc ${ }^{[1-10]}$, but the literatures were less which researching natural weathering crust colour ${ }^{[11-12]}$.In this paper, nephrite gravel, primary nephrite with natural weathering crust and artificial weathering crust imitation were tested by means of magnifier, gemmological microscope, ultraviolet-visible absorption spectroscopy (UVS), and scanning electron microscopy and energy spectrometer (SEM-EDXRF) so as to explore the reguler and characteristics of natural and artificial weathering crust colour. Based on comparing and researching various types of weathering crust colour, this paper provides a theoretical basis and feasible methods to identify nephrite gravel and its imitation.

\section{Experiments}

Specimens and Experiment Method.

$\mathrm{N} 1$ and N2 are the samples of nephrite gravel (alluvial deposits nephrite) respectively from Hetian, China and Baikal district, Russia, N3 and N4 are the samples of primary nephrite with natural weathering crust respectively from Xinjiang, China and Chuncheon district, South Korea, 
F1 and F2 are the samples of artificial weathering crust imitation from the market.

UV-visible absorption spectrum were recorded in the range of 250 1000nm using OCEAN OPTICS company production of GEM-3000 American ultraviolet visible spectrometer at a resolution of $1 \mathrm{~nm}$, the signal to noise ratio of $1000: 1$, the integral time $109 \mathrm{~ms}$, the 20 average number, the 1 smoothness. Scanning electron microscopy and energy spectrum (SEM-EDXRF) were recorded using Philips type XL-30ESEM environmental scanning electron microscope, at $20 \mathrm{kV}$ and high vacuum environment.

\section{Results and Discussion}

\section{Identification based on the surface characteristics.}

Sweat pores features of nephrite gravel. Nephrite gravel appears commonly the surface features of resembling "sweat pores". The "sweat pores" are impacted voids which formed on natural secondary weathering crust duo to mutual collision in the formation process of alluvial deposit gravel and its gloss is basically the same as nephrite gravel surface due to water constantly scour. The "sweat pores" in the surface of nephrite gravel (N1 and N2 samples) are very irregular, the size are not uniform, the edges are not smooth, and the shape are varied such as dished concave, triangular scar, and little impact point shape etc. The crust between the "sweat pores" and the "sweat pores" is outer smooth surface of nephrite gravel (see Fig. 1a), some "sweat pores" are connected togather (see Fig. 1b), and some "sweat pores" contain the smaller "sweat pores" which look like an island and zonal distribution (see Fig. 1c). There are some black dots irregular distribution in the surface and inside of nephrite gravel, which mainly are magnetite or graphite (see Fig. 1d). Because

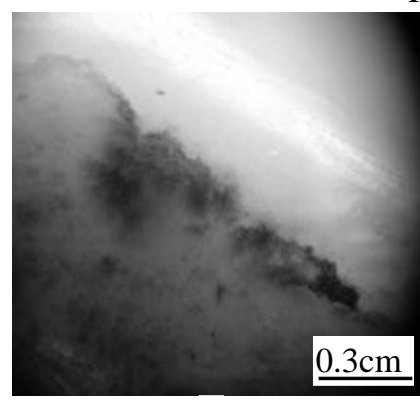

a

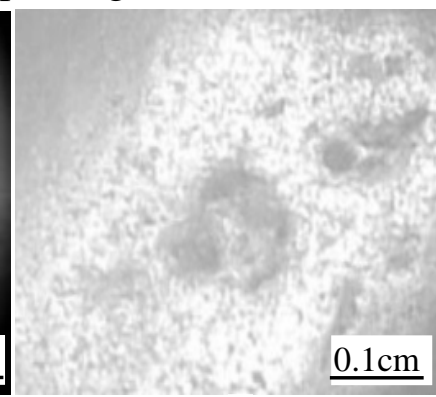

b

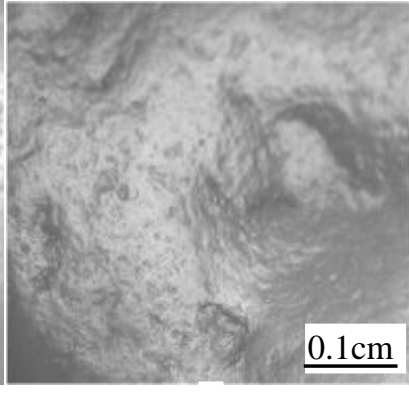

C

Fig. 1 "Sweat pores" morphology of nephrite gravel

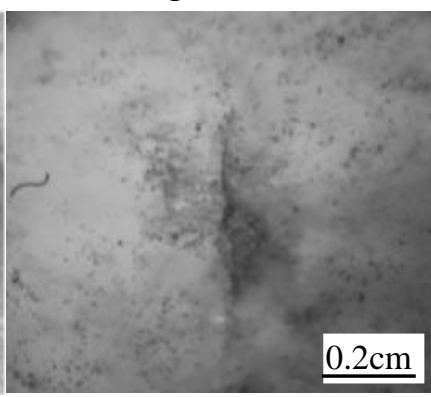

d

no mutual collision and water erosion constantly, there are no "sweat pores" in primary nephrite. Currently the primary nephrite grinding is often taken spraying stainless steel sand or acid etching to imitate the "sweat pores" of nephrite gravel, which the size is uniform, distribution is more consistent, the edges and inside are respectively steep and smooth, so it is evident difference from scattered and irregular "sweat pores" of nephrite gravel. Acid etching makes the surface structure become more loose and remove some black dots (graphite or magnetite), and gloss is not strong which is clear difference from the similarity of the gloss between the surface and the "sweat pores" for nephrite gravel.

Nail pattern features of nephrite gravel.Nephrite gravel appears commonly the surface features of resembling “nail pattern”. The caving rocks gradually separated jade from rock and formed an independent or semi-independent jade piece under floods impact power, which was moved to river after thousands of years. Some caving primary nephrites often were trapped in rubble, so branch various sizes of miscellaneous stone repeatedly rubbed some part of the jade and formed the "nail pattern" . When floods came again, nephrite often was trapped again in rubble after turned and moved a certain distance, which were frictionated by the size of miscellaneous stone. So repeatedly, the epiderm of nephrite gravel (N1 and N2 samples) was left many seemingly "nail pattern" (see Fig. 2), whose position is irregular and size is different. Nowadays, the imitation often appears the so-called "nail pattern" caused by grindstone, which often is found regularity and significant difference from the natural "nail pattern", and the "nail pattern" of nephrite gravel often is the epiderm with color. 


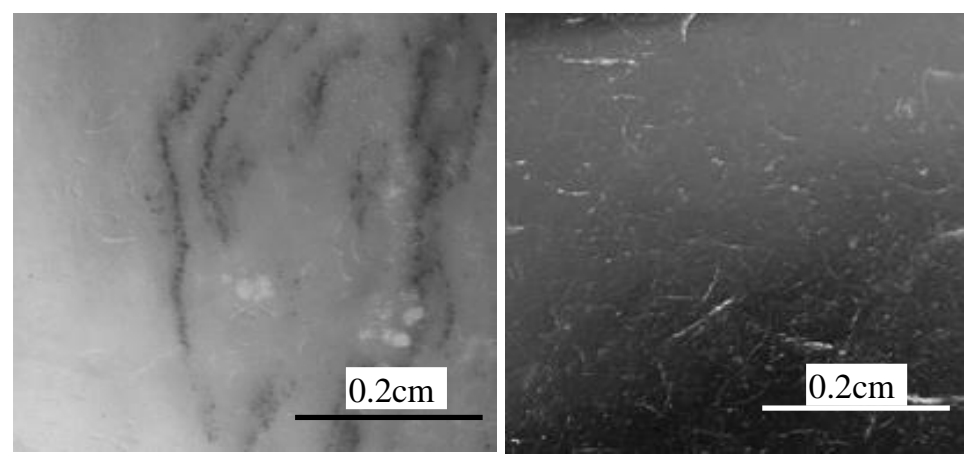

Fig. 2 “Nail patterns” morphology of nephrite gravel

\section{Identification based on color hue and its distribution.}

Colored weathering crust imitation (F1 sample) shows bright colors, which presents in the epidermis and fissures and no sense of nature transition hierarchy (see Fig. 3a). Chemical dyed imitation (F2 sample) often is dry surface and fake crust color occures in nephrite loose part (see Fig. 3b), which chemicals destroyed the nephrite surface structure and fading is easy to use boiling water cleaning or $\mathrm{NaClO}$ solution cleaning or heating above $100^{\circ} \mathrm{C}$ (see Fig. 3c). The dye often concentrates along the fissures, which is deep outside the cracks and gradually becomes pale inside the cracks (see Fig. 3d).

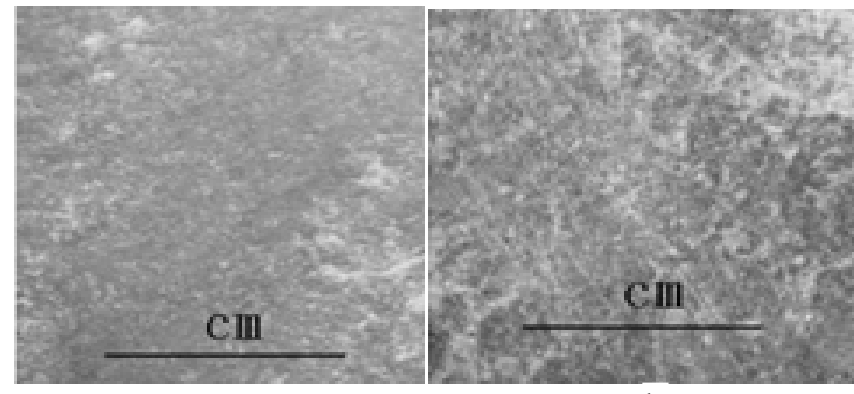

a b

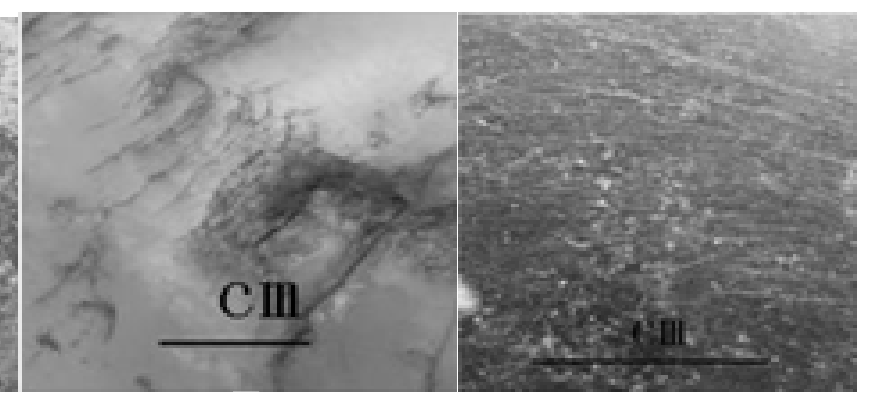

C

d

Fig. 3 Morphology of colored weathering crust imitation

The nephrite gravel was frequently collided in the river and usually formed a large number of micro cracks in the weathering crust. If the cracks were formed first, the color precipitated in the crack and diffused slowly to its both sides. Conversely, if the cracks were formed later, there is no color precipitated in the crack. Because colorless fissure is rare in the nephrite gravel, if there are a large number of non filled cracks in the weathering crust, which show usually that the nephrite gravel is dyeing imitation. The nephrite gravel (N1 and N2 samples) usually shows dendrite growth pattern for natural secondary weathering crust colour (see Fig. 4), while the crust color of dyeing primary nephrite is depth along the crack, and only a few samples diffused spread to both sides of the crack, which may improve the diffusion ability under high temperature dyeing.
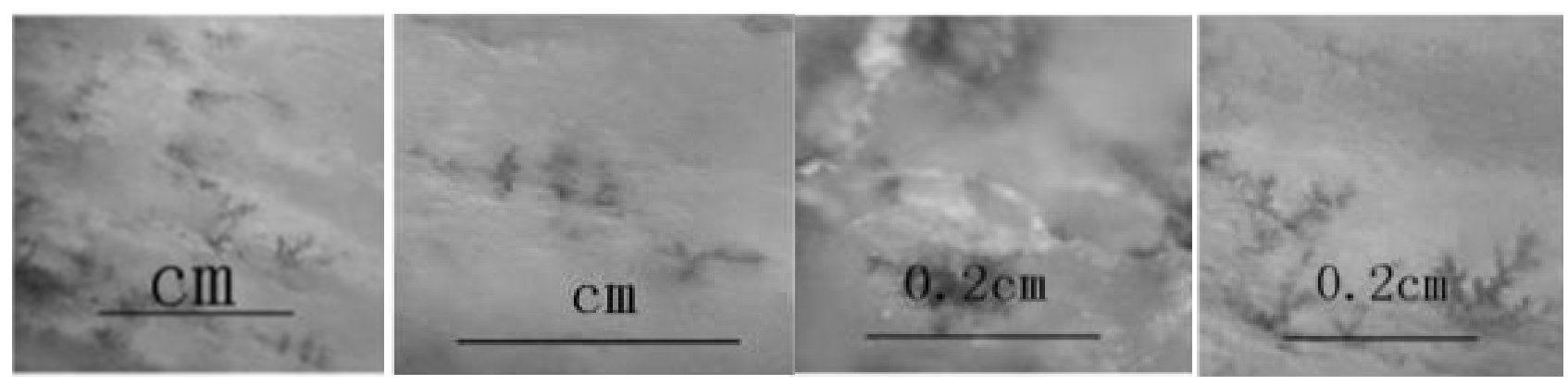

Fig. 4 Dendrite growth pattern for secondary weathering crust color of nephrite gravel

\section{Instrument identification for nephrite gravel and its imitation.}

UV-visible absorption spectrum analysis. The natural black, yellow, and brown secondary weathering crusts for $\mathrm{N} 1$ and N3 samples were measured by UVS, their absorption peaks are relate to $\mathrm{Fe}^{3+}$ and $\mathrm{Fe}^{2+}$ for lightwave selective absorption (see Fig. 5 a) , such as near $985 \mathrm{~nm}$ 
strong absorption band attributable to $\mathrm{Fe}^{2+}{ }^{5} \mathrm{D} \rightarrow{ }^{5} \mathrm{~T}_{2 \mathrm{~g}} \rightarrow{ }^{5} \mathrm{E}_{\mathrm{g}}$ electronic spin jump, $450 \mathrm{~nm}$ weak absorption band attributable to $\mathrm{Fe}^{3+}{ }^{6} \mathrm{~A} 1 \rightarrow{ }^{4} \mathrm{E}+{ }^{4} \mathrm{~A}(\mathrm{G})$ spectral phase transition, $372 \mathrm{~nm}$ strong absorption peak attributable to $\mathrm{Fe}^{+3}{ }^{6} \mathrm{~A}_{1} \rightarrow{ }^{4} \mathrm{E}\left({ }^{4} \mathrm{D}\right) \mathrm{d}$-d electronic transitions, near $280 \mathrm{~nm}$ absorption band attributed to $\mathrm{O}^{2-} \rightarrow \mathrm{Fe}^{3+}$. While the absorption spectrum of artificial yellow, and
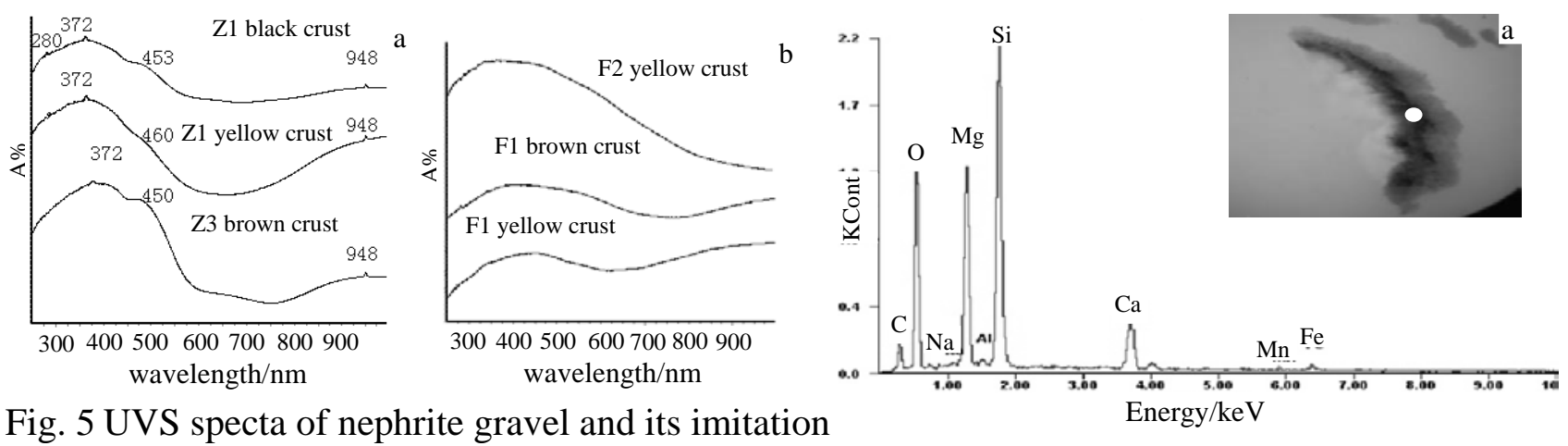

Fig. 5 UVS specta of nephrite gravel and its imitation


Fig. 6 Compositions of the natural weathering crust and the matrix for Z1 sample


Fig. 7 Compositions of the natural weathering crust and the matrix for Z2 sample
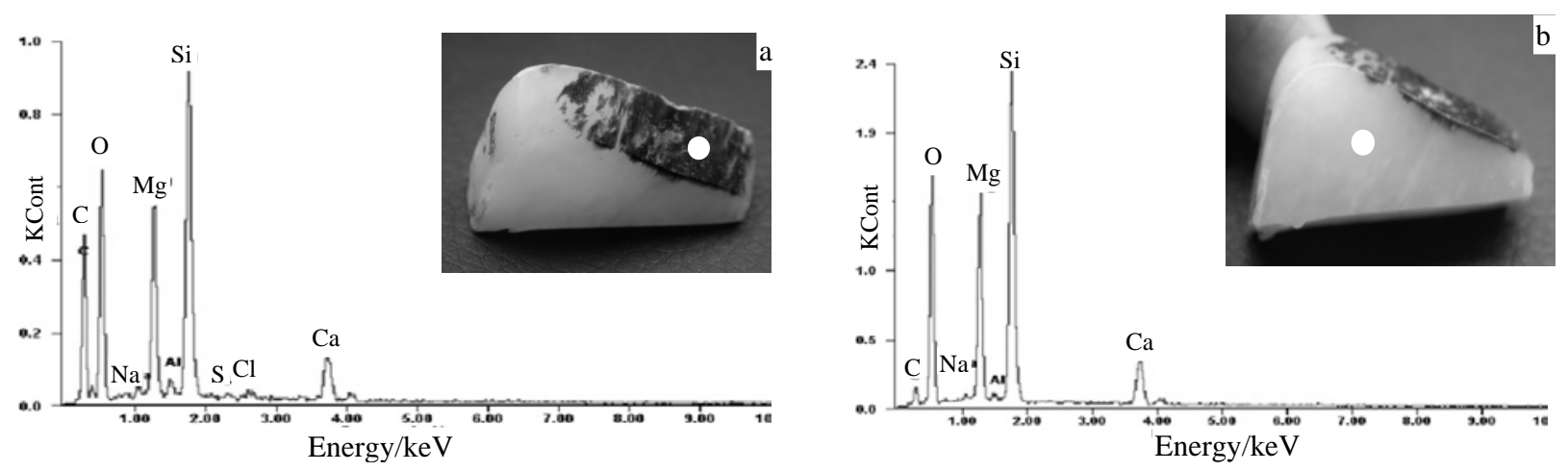

Fig. 8 Compositions of the artificial weathering crust and the matrix for F1 sample 

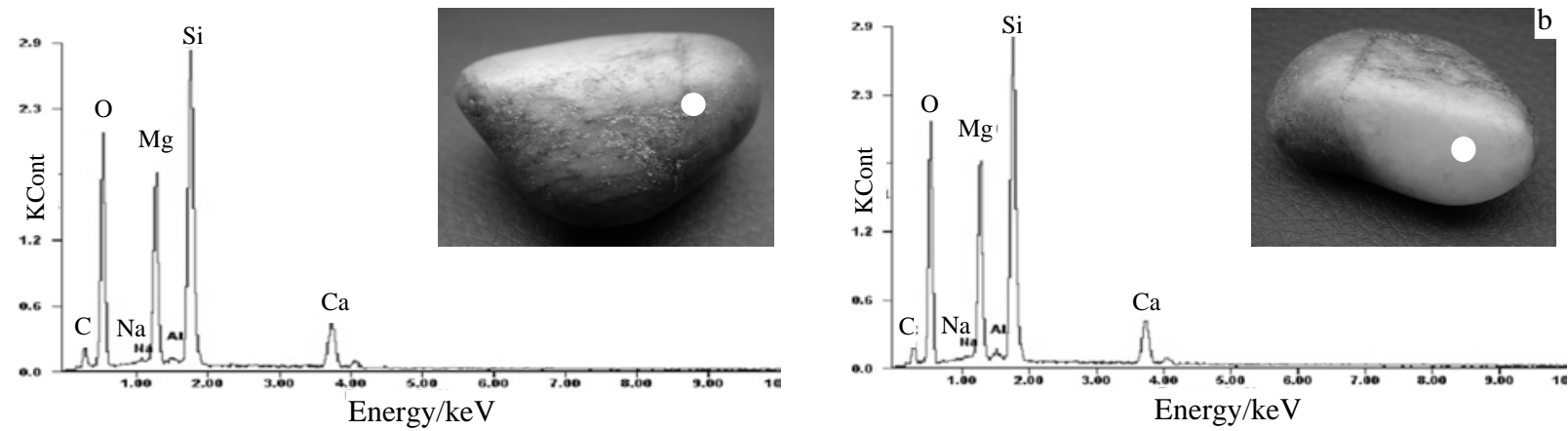

Fig. 9 Compositions of the artificial weathering crust and the matrix for F2 sample

brown crusts for F1 and F2 samples show the large absorption bands extending from ultraviolet to visible region (see Fig. 5 b), and Fe and Mn are not detected by SEM-XREDS, which is evident difference from the absorption band of the natural secondary crust color. The UVS spectra for N2 and N4 samples with the ones of N1 and N3 sample are the same, so only N1 and N3 spectra are shown in this paper.

Scanning electron microscope and energy spectrometer analysis. Z1 sample mainly occurs in natural black, brown, and yellow secondary weathering crust, which the peaks of Fe and Mn were detected (see Fig 6 a and Fig. 6 b), and Z3 sample is mainly natural brown secondary weathering crust, which the peaks of Fe was detected (see Fig. 7 a ), so it indicates that the black, yellow, and brown secondary weathering crust for nephrite gravel are mainly relate to $\mathrm{Fe}$ and $\mathrm{Mn}$, and the secondary weathering crust color for primary nephrite is mainly relate to Fe. F1 and F2 samples are dyed brown, and yellow crust imitation of nephrite gravel, respectively, which the peaks of Fe and Mn were not detected in dyed brown crust and yellow crust (see Fig. 8 a and Fig. 9 a). LA-ICP-MS test results show that the content of Co was higher in dyed black crust of nephrite gravel imitation, which indicates that use dye containing Co salt. The formation of natural black and dark brown crust may be related to the increase of Mn content or disseminated by $\mathrm{C}, \mathrm{H}, \mathrm{N}$ and $\mathrm{S}$ in rich humus soil. Fig.6 c and Fig.7 b-Fig.9 b show also that the matrix compositions of nephrite gravel and its imitation is the same. The EDXRF peaks for N2 and N4 samples with the ones of N1 and N3 sample are the same, so only N1 and N3 peaks are shown in this paper.

\section{Conclusion}

1) Colored weathering crust imitation shows bright colors, which presents in the epidermis and fissures and no sense of nature transition hierarchy, while nephrite gravel shows the surface features as "sweat pores" and "nail pattern", and dendrite growth pattern for natural secondary weathering crust colour, which is evident difference from primary nephrite with natural weathering crust and artificial weathering crust imitation, and can be regarded as the identification characteristics.

2) The absorption peaks of natural black, yellow, and brown secondary weathering crust for nephrite gravel are relate to $\mathrm{Fe}^{3+}$ and $\mathrm{Fe}^{2+}$ for lightwave selective, while the absorption spectra of artificial yellow crust and brown crust imitation show the large absorption band extending from the ultraviolet to the visible region, and Fe and Mn are not detected by SEM-EDXRF, which is evident difference from the absorption band of natural secondary weathering crust color for nephrite gravel and primary nephrite.

3) The black, yellow, and brown secondary weathering crust for nephrite gravel are mainly relate to $\mathrm{Fe}$ and $\mathrm{Mn}$, and the secondary weathering crust color for primary nephrite is mainly relate to $\mathrm{Fe}$, while Fe and Mn are not detected in dyed brown crust and yellow crust of nephrite gravel imitation, which is the basis for the identification of nephrite gravel and its imitation. 


\section{References}

[1] C.J.Adamsa, R.J.Beckb, H.J.Campbella. Characterisation and origin of New Zealand nephrite jade using its strontium isotopic signature [J]. Lithos. 2007:97 (3-4):307-322.

[2] Zidarov N., Kostov R.I., Zidarov P.. Nephrite bearing tremolitite. First find in South-West Bulgaria. Comptes Rendus de L'Academie Bulgare des Sciences. 2010:63 (12):1771-1780.

[3] Liu Y.,Deng J.,Shi G.,Sun X.,Yang L. Geochemistry and petrogenesis of placer nephrite from Hetian, Xinjiang, Northwest China [J]. Ore Geology Reviews. 2011:41 (1):122-132.

[4] Gil, G. Petrographic and microprobe study of nephrites from Lower Silesia (SW Poland) [J]. Geological Quarterly. 2013:57(3):395-404.

[5] Ling X., Schmädicke E., Wu R, Wang S.. Composition and distinction of white nephrite from Asian deposits [J]. Neues Jahrbuch fur Mineralogie, Abhandlungen. 2013:190 (1):49-65.

[6] Shi Miao, Yu Bingsong, Guo Ying, Yuan Ye, Ng Yi Nok. Structural and mineralogical characterization of green nephrite in Hetian, Xinjiang, China [J]. Key Engineering Materials. 2014:633:159-164.

[7] Burtseva M.V., Ripp G.S., Posokhov V.F., Zyablitsev A. Yu., Murzintseva A.E. The sources of fluids for the formation of nephritic rocks of the southern folded belt of the Siberian Craton [J]. Doklady Earth Sciences. 2015:460 (1):82-86.

[8] Burtseva M.V, Ripp G.S, Posokhov V.F, Murzintseva A.E. Nephrites of East Siberia: Geochemical features and problems of genesis [J]. Russian Geology and Geophysics. 2015:56(3):402-410.

[9] Arkhireev I.E., Makagonov E.P., Belyatskii B.V., Maslennikov V.V.. Age of nephrite-bearing dikes of the Uzunkyr Belt (South Urals): Local U-Pb isotope analysis of zircon and Sr-Nd isotope data of rock-forming minerals [J]. Doklady Earth Sciences. 2012:442 (1):70-75.

[10]Yui Tzen-Fu, Kwon Sung-Tack. Origin of a dolomite-related jade deposit at Chuncheon, Korea[J]. Economic Geology. 2002:97 (3):593-601.

[11]Wilkins C.J.,Tennant W.C.,Williamson B.E., McCammon C.A. Spectroscopic and related evidence on the coloring and constitution of New Zealand jade [J]. American Mineralogist. 2003:88(8-9):1336-1344.

[12]Grapes R. H.,Yun S. T. Geochemistry of a New Zealand nephrite weathering rind [J]. New Zealand Journal of Geology and Geophysics. 2010:53 (4):413-426. 